\title{
The Effect of Meal Pace on Customer Satisfaction
}

\author{
by BREFFNI M. NOONE, SHERYL E. KIMES, ANNA S. MATTILA, and JOCHEN WIRTZ
}

Restaurant operators who seek to increase table turns during peak periods may want to speed up the meal's pace. However, excessive speed may make customers feel rushed. A survey of 218 respondents found that too fast a pace does affect customer satisfaction with the meal experience, with fine-dining customers more sensitive to pacing issues than customers in casual or upscale casual restaurants. Regardless of restaurant type, too fast a pace during the meal itself diminishes customer satisfaction, but speed during check settlement is often appreciated. The effects on customer satisfaction of the pace of welcome, seating, and taking drink orders depend partly on the type of restaurant and on the meal type. Guests at fine-dining restaurants do not want these preprocess events to be rushed. Additionally, a faster pace during these preprocess events at dinner diminished satisfaction ratings as compared to lunch.

Keywords: restaurant management; revenue management; service pacing $\neg$ he goal of revenue management is to maximize revenue by means of variable pricing and duration controls (Kimes and Chase 1998). Revenue management has traditionally been applied in service settings where services are sold to the consumer for a fixed amount of time (e.g., a number of nights in a hotel or flights of specified duration on an airplane) (Kimes 1989; Hanks, Cross, and Noland 1992; Smith, Leimkuhler, and Darrow 1992). Restaurants have used a form of revenue management for years, notably with early bird specials and other pricing strategies to influence demand. More recently, restaurants have joined other services to use duration-based revenue management approaches. In this regard, restaurants face the same problem as, for example, health care facilities, casinos, and golf courses, in that the length of customer use of the service is not set in advance (Kimes et al. 1998; Kimes 2000; Secomandi et al. 2002; Kimes and Wirtz 2003). In a restaurant, where the duration of the dining experience can vary substantially, the goal of 
revenue management is usually to reduce or control dining duration, while not unduly interfering with check averages. If restaurant providers can reduce dining duration during periods of high demand, they will be able to serve more customers, which, in turn, will lead to increases in revenues generated.

A focus on reducing dining duration may yield favorable results, but it may have an effect on customer satisfaction. Any action taken by a restaurant operator to reduce dining duration may be perceived by the customer as a change in the nature of the experience (Kimes, Wirtz, and Noone 2002). To date, we have seen little empirical research that assesses the potential negative effect that increasing the pace of the dining experience may have on customer satisfaction. Other businesses take steps to control the pace of service. Theme parks, for instance, use queues to control the pace at which guests can enjoy attractions, but long queues can leave guests unhappy with their experience. Golf courses employ marshals who regulate the flow of play to reduce delays for fast players and enable the sale of additional tee times, but casual players may feel forced into an undesired increase in the pace of play. If customers feel unduly rushed or delayed, they may be dissatisfied and discontinue their patronage (Kimes and Wirtz 2002; Wirtz et al. 2003).

Before applying any type of revenue management approach to reduce dining duration, it is important that restaurant operators understand how consumers perceive and react to manipulations in the pace of the dining experience. The primary purpose of the research described in this article was to empirically test the relationship between the pace of the dining experience and customer satisfaction. In particular, we wanted to determine whether consumers are sensitive to changes in the pace of different service stages. We begin by examining the potential revenue and customer satisfaction implications of increasing the pace of the dining experience. We then present the results of a survey that we used to examine the relationship between pace and customer satisfaction. Finally, we discuss the implications of our findings for restaurant operators.

\section{Pace and Customer Satisfaction}

The advantages to restaurant operators of reducing dining duration during peak demand periods include shorter wait times for tables, reduced likelihood of losing customers due to excessive waits, and an increase in covers and revenues. While these outcomes are appealing for operators, the benefits to consumers (other than shorter wait times) are less clear. A key issue to consider, from the customers' perspective, is whether increasing the pace of an experience will diminish their satisfaction with that experience.

Most of the research that has been done in relation to the time aspect of service experiences has focused on wait time. Lengthy wait time has been shown to diminish customer satisfaction and customer evaluations for such services as restaurants, banks, and airlines (see, e.g., Taylor 1994; Tom and Lucey 1997; Pruyn and Smidts 1998). Furthermore, it has been shown that it is perceived wait time, not actual wait time, that has the greatest effect on customer satisfaction (see, e.g., Katz, Larson, and Larson 1991; Pruyn and Smidts 1998).

Given evidence that wait time contributes to customer dissatisfaction and reduces evaluations of service, approaches to influencing wait time have been investigated in the operations management and marketing literature. Focusing on reducing wait time, operations management researchers have proposed several approaches, including improving service process and workstation design, forecasting demand more accurately, reducing set-up times, and cross-training employees (Sill 1991; Davis and Maggard 1994; Jones and Dent 1994; Sheu and Babbar 1996). Marketing researchers have examined practices that 
influence perceived wait time, including altering the service environment (e.g., providing a news board, memorabilia in theme restaurants), managing employee visibility, filling customers' time (e.g., providing menus in restaurants), and providing information regarding the waiting times. A number of studies have empirically tested whether such actions improve service evaluations (Katz, Larson, and Larson 1991; Hui and Tse 1996). Retailers and service operators are also increasingly adapting technology such as selfcheckout lines, pagers, and remote-ordering terminals to make waiting more palatable (New-Fielding 2002; Higgins 2004).

While faster may be better for conveniencebased services, this may not hold for pleasure-driven services. For example, in service environments such as restaurants (perhaps with the exception of most quickservice restaurants), theme parks, and golf courses, customers probably will not want to minimize the duration of their experience. In fact, they might even want to maximize their enjoyment by extending their experience.

A number of articles published in the popular press provide anecdotal evidence of customers' dislike of practices intended to speed up golf play or restaurant meals (Szuchman and Tesoriero 2004; Bhatia 2002). These anecdotal findings underscore the necessity to gain a clearer understanding of the relationship between customers' perceptions of the pace of a dining experience and their satisfaction with that experience. We propose that an inappropriately slow pace leads to feelings of anxiety and frustration as the customer is waiting for the next step. Conversely, when the pace is too fast, the customer is unable to linger and savor the experience.

Service Stage, Pace, and Satisfaction

Research on wait time has also shown that customers' reaction to waiting for service often depends on the stage of the experience. The dining experience can be broken into three stages: (1) the preprocess stage, which extends from a customer's arrival at the restaurant until he or she orders the meal; (2) the in-process stage, which involves placing an order and consuming the meal; and (3) the postprocess stage, which begins with check settlement and ends when the customer leaves (Dubé-Rioux, Schmitt, and Leclerc 1989). Customers have been shown to be more upset when a delay occurred during the preprocess or postprocess stages of the dining experience than when a delay occurred during the in-process stage, even though the delay was of the same length in each stage (Dubé-Rioux, Schmitt, and Leclerc 1989). Although our research is about speeding up the pace, the findings on reactions to delays suggest that customers may be more amenable to a faster pace during the preprocess and postprocess stages of the dining experience than during the meal itself (the inprocess stage).

\section{Restaurant Norms, Pace, and Satisfaction}

Previous research has shown that customer satisfaction is influenced by experience-based norms (Woodruff, Cadotte, and Jenkins 1983). That is, customers' experience with a service generates expectations that serve as a framework for evaluating the service on subsequent occasions. Any confirmation or disconfirmation is related to those norms, as is satisfaction.

Correspondingly, we propose that the effect of pace on satisfaction may be influenced by the norms that customers associate with a particular type of restaurant. In that regard, we expect that customers would be more tolerant of a faster pace in a casual restaurant, for instance, than in a fine-dining restaurant. Additionally, we expect that meal type (i.e., lunch or dinner) will influence customers' reactions to the pace of the dining experience. Specifically, we expect that 
customers will accept a faster pace for lunch than they do for dinner. Finally, we propose that the occasion (i.e., social, business, or convenience) will influence a customer's reaction to the pace of a dining experience. For example, we expect that customers would display a greater tolerance of a faster pace when they are dining for convenience than when they are dining for social reasons.

\section{Research Procedure}

A self-administered survey was used to test the effect of the pace of the dining experience on customer satisfaction. We mailed the survey to 580 people who were members of a handicraft association, parents of students at a university located in the northeastern United States, and employees of a clinical research organization. We asked them to respond if they had dined in a sit-down restaurant within the previous three weeks. To encourage participation, we offered a drawing for gift certificates at a number of service outlets.

At the beginning of the survey, we asked respondents to write a description of their recent dining experience. For the purpose of this study, we asked respondents to rate their experience from the time they sat down at the table to the time they stood up. ${ }^{1}$ To make sure that respondents checked the appropriate restaurant type, we included on the questionnaire a description of each restaurant type, including the average check per person and examples of popular chain restaurants.

To make sure that we had responses covering different meal paces, we sent out equal numbers of three versions of the questionnaire. Thus, one questionnaire examined a moderate-pace experience, another looked at a slow-pace meal, and the third version asked respondents to consider a fast-pace experience. (A sample of the questionnaire appears in the appendix.) We were careful not to characterize slow or fast as necessarily negative (or positive) conditions. Respondents were also asked a number of general questions in relation to the experience they recalled for the questionnaire, including how recent was their experience and whether their purpose was convenience, business, or social (which comprised a meal with family or friends and a special occasion or celebration).

Respondents were then asked to answer questions to measure their perceptions of pace and satisfaction. Given our proposal that satisfaction with the pace of service depends on the stage of the meal, we measured respondents' perceptions of pace and satisfaction for each stage of the dining experience and their overall evaluation of the service encounter. To aid recall, we provided respondents with a description of the relevant stage of the dining experience immediately before the questions relating to that stage of the experience. The definitions of service stages used in the study, which were largely consistent with previous research, are shown in Exhibit 1 (Dubé-Rioux, Schmitt, and Leclerc 1989).

\section{Measures}

Perceived pace was measured using two 7-point items. One item was, "How would you describe the pace of the meal [stage]? (extremely fast to extremely slow)"; and the other asked, "How would you describe

1. For the purpose of this study, a restaurant service encounter was defined as beginning when a party is seated at its table and ending when the party vacates the table. It could be argued that the service encounter begins when the party enters the restaurant. However, the narrower definition used in this study reflects the revenue management objective of maximizing the revenue generated per unit of inventory, that is, a seat at a table. Therefore, it is time spent at the table that was relevant in this study, and not time spent waiting for a table. 


\section{Exhibit 1:}

Service Stage Definitions

Preprocess stage: This stage begins at the time that a party is seated at a table up to, and including, the point at which the first food course is delivered to the table. Typical interactions that occur during this stage include being greeted by the server, ordering and delivery of drinks, ordering food, and delivery of the first food course.

In-process stage: This stage begins at the time that a party receives the first food course and lasts up until the point in time that either (1) the party requests the check or (2) the server automatically delivers the check (i.e., without the party having requested it). Typical activities that occur during this stage include the clearing of plates and glassware, the delivery of entrées, the ordering and delivery of dessert and coffee, and the request for (or automatic delivery of) the check.

Postprocess stage: This stage is defined as beginning at the time that either (1) the party requests the check or (2) the server automatically delivers the check, and lasts up to the time that the party vacates the table. Typical activities that occur during this stage include the clearing of dessert plates and other items from the table, coffee refills, the delivery of the check and collection for processing, and the return of the check to the table.

the duration of the meal [stage]? (extremely short to extremely long)." "Satisfaction was measured using Westbrook and Oliver's (1981) six-item, 7-point bipolar scale. ${ }^{3}$

\section{Sample}

A total of 228 questionnaires were returned (39 percent response rate). We had to discard 10 of these responses, because the experience rated on the questionnaire was beyond our three-week cutoff point. Just more than half of the responses (56 percent; $n=123$ ) involved a meal within the previous week, 17 percent $(n=38)$ recalled a meal within the prior two weeks, and the remaining 26.2 percent $(n=57)$ of the questionnaires involved a meal as old as three weeks. Of the respondents, 69 percent $(n=150)$ were female, and the majority of respondents ( 87 percent, $n=189$ ) were between thirty-five and fifty-five years of age.

The distribution of restaurant type was reasonably even. Thirty-five percent $(n=$ 77) of responses covered casual restaurants, 37 percent $(n=81)$ involved upscale casual restaurants, and 28 percent $(n=60)$ rated a fine-dining experience. The majority of questionnaires (72 percent; $n=158$ ) rated a dinner experience. Many respondents (71 percent; $n=154$ ) had previously dined in the restaurant. Social purposes was the foremost reason for dining (69 percent; $n=151$ ), while 30 questionnaires (14 percent) involved a business meal, and convenience was the purpose for 17 percent $(n=37)$ of respondents. The mean ratings for perceived pace, by pace condition and restaurant type are provided in Exhibit 2.

2. Cronbach's alpha $=.83$ (overall service encounter), .76 (preprocess), .81 (in-process), and .83 (postprocess).

3. See Westbrook and Oliver (1981). Cronbach's alpha $=.99$ (overall service encounter), 98 (preprocess), .99 (in-process), and .98 (postprocess). 


\section{Exhibit 2:}

Means for Respondents' Evaluation of Pace, by Pace Condition and Restaurant Type (Perceived Pace: $1=$ Extremely Slow, 7 = Extremely Fast $)$

\begin{tabular}{|c|c|c|c|c|c|c|c|c|c|}
\hline \multirow[b]{3}{*}{ Pace Condition } & \multicolumn{9}{|c|}{ Restaurant Type } \\
\hline & \multicolumn{3}{|c|}{ Casual } & \multicolumn{3}{|c|}{ Upscale Casual } & \multicolumn{3}{|c|}{ Fine Dining } \\
\hline & $\begin{array}{c}\text { Fast } \\
(\mathrm{n}=32)\end{array}$ & $\begin{array}{l}\text { Moderate } \\
(\mathrm{n}=24)\end{array}$ & $\begin{array}{c}\text { Slow } \\
(\mathrm{n}=21)\end{array}$ & $\begin{array}{c}\text { Fast } \\
(\mathrm{n}=26)\end{array}$ & $\begin{array}{c}\text { Moderate } \\
(\mathrm{n}=27)\end{array}$ & $\begin{array}{c}\text { Slow } \\
(\mathrm{n}=28)\end{array}$ & $\begin{array}{c}\text { Fast } \\
(\mathrm{n}=24)\end{array}$ & $\begin{array}{c}\text { Moderate } \\
(\mathrm{n}=18)\end{array}$ & $\begin{array}{c}\text { Slow } \\
(\mathrm{n}=18)\end{array}$ \\
\hline Preprocess & 5.22 & 4.54 & 2.80 & 5.30 & 4.25 & 3.16 & 4.46 & 4.00 & 3.22 \\
\hline In-process & 5.09 & 4.16 & 2.94 & 4.96 & 4.11 & 3.20 & 4.46 & 4.00 & 3.33 \\
\hline Postprocess & 5.10 & 4.71 & 4.15 & 5.23 & 4.55 & 3.47 & 4.58 & 4.28 & 3.44 \\
\hline $\begin{array}{l}\text { Overall service } \\
\text { encounter }\end{array}$ & 5.09 & 4.54 & 2.65 & 5.26 & 4.14 & 3.00 & 4.58 & 3.85 & 3.11 \\
\hline
\end{tabular}

\section{The Effect of Pace on} Satisfaction

To test the effect of dining experience pace on satisfaction, we ran a polynomial regression analysis with satisfaction as the dependent variable and pace as the predictor variable. We controlled for the following variables: restaurant type, meal type, reason for dining, gender, age, and number of people in the party.

Our results indicate that respondents' perceptions of the pace of dining experiences affected their satisfaction with those experiences. When respondents perceived the pace of a dining experience as being either very fast or very slow, their satisfaction diminished. This relationship between pace and satisfaction applied to the dining experience as a whole and also to each individual stage of the experience.

The technical aspects of the regression analysis are as follows. The cubic term for pace was insignificant and was dropped from the analysis. A test of the difference between the $R^{2}$ for the quadratic model and the linear model was significant $(p<$ .005 ), providing support for the inclusion of the quadratic pace term. The quadratic pace term was significant in all regression equations, including the regression of overall satisfaction on overall pace and the regressions of satisfaction on pace for each of the three stages of the dining experience. Exhibit 3 summarizes the key regression results. The negative sign of the coefficient for the quadratic pace term indicates that the curve turns down from its maximum point. This is reflected in the plot of perceived pace and satisfaction, derived using the standardized beta coefficients for the pace terms, in Exhibit $4 .^{4}$

\section{Meal Stage}

When we tested for the effect of service stage on the relationship between perceived pace and service stage satisfaction, we found that respondents had a much greater tolerance for a fast pace in the postprocess stage than during the preprocess and inprocess stages of the dining experience..$^{5}$

4. Standardized beta coefficients, as opposed to raw data points, were used to better facilitate the detection of the nature of the relationship between pace and satisfaction.

5. The in-process stage was used as the reference group to test the interaction between pace and service stage. To satisfy the independence-of-observations assumption required for regression analysis, a data set comprising three data subsets was generated. Every third observation from the set of all observations was selected for 


\section{Exhibit 3:}

Regression Analysis Results: Perceived Pace and Satisfaction

\begin{tabular}{|c|c|c|c|c|c|c|c|c|}
\hline \multirow{3}{*}{$\begin{array}{l}\text { Independent } \\
\text { Variable }\end{array}$} & \multicolumn{8}{|c|}{ Dependent Variable } \\
\hline & \multicolumn{2}{|c|}{$\begin{array}{c}\text { Overall Service } \\
\text { Encounter } \\
\text { Satisfaction }\end{array}$} & \multicolumn{2}{|c|}{$\begin{array}{l}\text { Preprocess } \\
\text { Stage } \\
\text { Satisfaction }\end{array}$} & \multicolumn{2}{|c|}{$\begin{array}{c}\text { In-Process } \\
\text { Stage Satisfaction }\end{array}$} & \multicolumn{2}{|c|}{$\begin{array}{c}\text { Postprocess } \\
\text { Stage Satisfaction }\end{array}$} \\
\hline & Coefficient & t-Value & Coefficient & t-Value & Coefficient & t-Value & Coefficient & $\mathrm{t}$-Value \\
\hline $\begin{array}{l}\text { Pace } \\
\text { Pace }^{2}\end{array}$ & $\begin{array}{r}.48 \\
-.17\end{array}$ & $\begin{array}{c}7.14^{*} \\
-4.83^{*}\end{array}$ & $\begin{array}{r}.45 \\
-18\end{array}$ & $\begin{array}{r}7.50^{*} \\
-5.96^{*}\end{array}$ & $\begin{array}{r}.43 \\
-.19\end{array}$ & $\begin{array}{r}6.31^{*} \\
-567^{*}\end{array}$ & $\begin{array}{r}.48 \\
-10\end{array}$ & $\begin{array}{c}7.64 * \\
-2.91 * *\end{array}$ \\
\hline $\mathrm{Pace}^{2}$ & -.17 & $-4.83^{*}$ & -.18 & $-5.96^{*}$ & -.19 & $-5.67^{*}$ & -.10 & $-2.91^{* *}$ \\
\hline
\end{tabular}

*Significant at $p<.001 . * *$ Significant at $p<.05$.

\section{Exhibit 4:}

Perceived Pace and Satisfaction

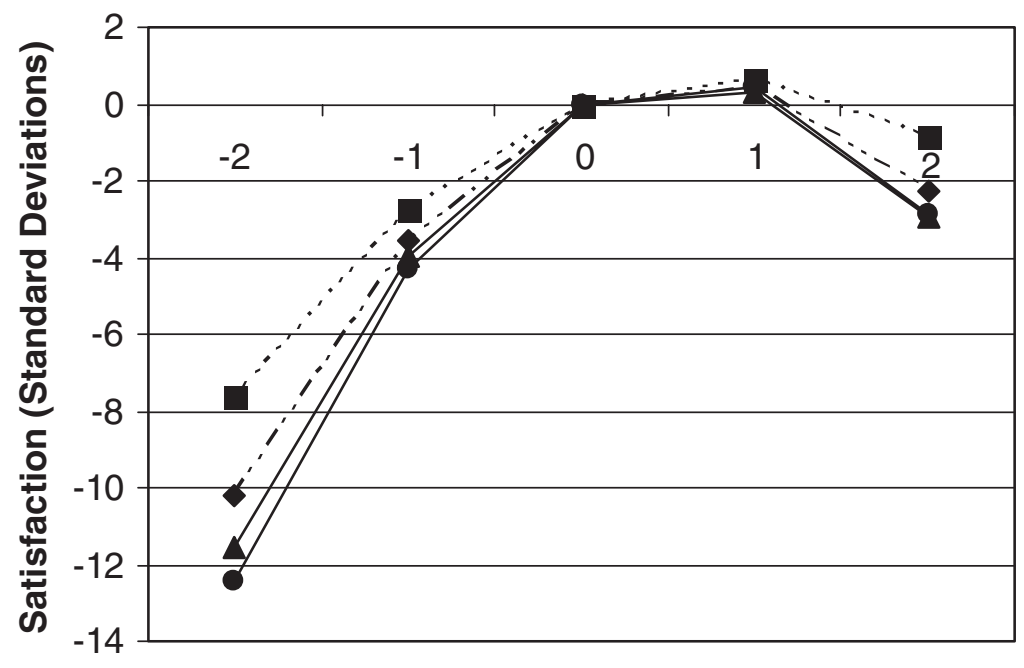

Perceived Pace (Standard Deviations)

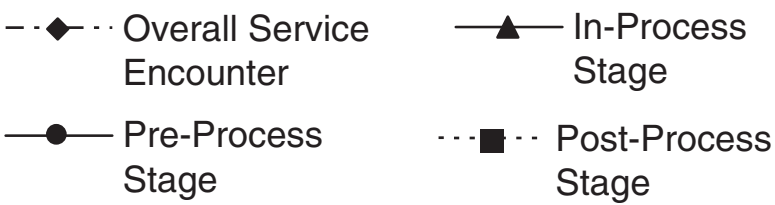

inclusion in the preprocess stage data subset. Then, every second observation from the remaining observations was placed in the in-process stage data subset, with the remaining observations placed in the postprocess data subset. The interaction was significant $(p<.05)$, and the effect of perceived pace on satisfaction for the post-process stage when compared with the in-process stage was marginally significantly $(p<.1)$. 
That said, we found that the pace of the inprocess stage had the greatest influence on satisfaction. When we tested for the effect on overall satisfaction of satisfaction with the individual service stage, the satisfaction variables for all three service stages were significant $(p<.001)$. However, the coefficient for in-process satisfaction (.66) was considerably larger than those for either the preprocess (.26) or postprocess stages (.15).

\section{Restaurant Type, Meal Type, and Reason for Dining}

We found that our respondents had clear pacing expectations for different restaurant types. Respondents gave lower satisfaction ratings when they felt rushed at a fine-dining restaurant than when the pace picked up in casual or upscale casual restaurants. ${ }^{6}$ Beyond that finding, meal type and reason for dining had no influence on the relationship between the overall pace of the dining experience and overall satisfaction with the experience.

The findings were different for specific stages, however. For the preprocess stage, the type of restaurant and meal type influenced the relationship between pace and satisfaction. Again, a fast pace in the preprocess stage meant low satisfaction ratings for fine-dining experiences, as compared to those of casual or upscale casual restaurants. ${ }^{7}$ Likewise, a fast preprocess pace at dinner diminished satisfaction ratings as compared to a speedy preprocess stage at lunch. ${ }^{8}$ Again, respondents' reason for dining did not influence the relationship between pace and their satisfaction during the preprocess stage.
None of the three restaurant environment attributes (restaurant type, meal type, or reason for dining) were found to influence the relationship between perceived pace and satisfaction for the inprocess and postprocess stages. Thus, the negative effects of a fast pace on satisfaction held for both stages irrespective of the restaurant type, meal type, or reason for dining.

\section{Discussion and Managerial Implications}

We found that customers are sensitive to the pace of dining experiences, particularly with regard to the meal itself. Consistent with previous work, we found that when the pace of the dining experience was perceived as being either too slow or unduly fast, customer satisfaction diminished (see, e.g., Katz, Larson, and Larson 1991; Pruyn and Smidts 1998). These findings provide empirical support for the anecdotal observations that we mentioned earlier (Szuchman and Tesoriero 2004; Bhatia 2002). Furthermore, we found that the stage of the dining experience influences the relationship between pace and satisfaction. This study provides empirical support for those experienced managers who believe that customers favor a faster pace during the postprocess stage of their dining experience and that they dislike being "rushed along" during the preprocess and in-process stages. We also found that the effect of pace on overall satisfaction with a dining experience varies by restaurant type, with fine-dining customers being most sensitive to pacing issues.

6. Casual restaurants were used as the reference group to test the interaction between pace and restaurant type. The interaction was significant $(p<.05)$, and the fine-dining category was significantly different to the casual category $(p<.05)$.

7. Casual restaurants were used as the reference group to test the interaction between pace and restaurant type. The interaction was significant $(p<.05)$, and the fine-dining category was significantly different from the casual category $(p<.05)$.

8. Lunch was used as the reference to test the interaction between pace and meal type. The interaction was significant $(p<.05)$, and the dinner category was significantly different from the lunch category $(p<.05)$. 
Additionally, restaurant type and meal type influence the relationship between pace and satisfaction for the preprocess stage of the dining experience.

Returning to our opening discussion of how to reduce dining duration for the purpose of revenue management, let us consider our findings as we examine ways to minimize potential customer dissatisfaction stemming from speeding up a meal.

1. Focus duration reduction efforts on the postprocess stage. It is clear from our findings that restaurateurs can speed up check settlement and departure (the postprocess stage). Regardless of the type of restaurant, meal type, or the reason for dining, respondents reported little reduction in dining satisfaction when the pace picked up during the postprocess stage, as compared to the rest of the meal. Actions that could be taken at this stage could include reducing the time for check delivery and processing. For example, significant time savings can be accrued through the use of handheld devices that print the bill and process credit card payments at the table. For most restaurants, speeding the postprocess stage is primarily a matter of training servers to make sure that parties are not forced to wait for a check when they are ready to settle.

2. Opportunities for reducing duration during the preprocess stage. Certain aspects of the preprocess stage can be quite brisk, despite the risk of diminishing satisfaction by rushing diners at this point. From our respondents' descriptions of their dining experiences, we see that a prompt greeting and prompt delivery of drinks actually improve guests' satisfaction, suggesting two key activities to target for duration reduction. Ensuring prompt service at this point is often a matter of the host assigning customers to servers in such a way that servers are available to give timely and appropriate attention to arriving customers. The host and servers must also be communicating to ensure that newly seated parties are not left alone for an extended time. Once the initial drinks are down, however, servers must be prepared to relax the pace, particularly when a first-time customer is examining the menu. Training programs for servers should encompass guidelines for identifying and addressing the needs of first-time customers as opposed to repeat customers. Simply stopping at the table to ask whether the party has questions about the menu can help the server provide appropriate pacing at this point.

3. Do not rush the meal itself. Any actions to reduce the duration of the in-process stage of the dining experience should be approached with caution. We found that customers are the most sensitive to pacing once the appetizers and entrées are served. Additionally, given that satisfaction with the in-process stage has the greatest impact on overall satisfaction, actions to reduce duration during this stage are most likely to drive customers away. We say this in view of the findings that customer satisfaction has been shown to be positively associated with customer retention (Anderson and Sullivan 1993; Bolton 1998), repurchase intent (LaBarbera and Mazursky 1983; Bolton and Drew 1991; Mittal, Pankaj, and Tsiros 1999), word-of-mouth behavior (Anderson 1998; Wirtz and Chew 2002), and usage levels (Bolton and Lemon 1999).

4. Greater opportunity to reduce duration exists in casual and upscale casual restaurants. Operators of casual and upscale casual restaurants can reduce duration particularly during the preprocess stage, but that stage should not be rushed in fine-dining restaurants. Our results indicated that a fast pace had less effect on overall satisfaction in casual and upscale casual restaurants than was found in fine-dining restaurants. This was also true for satisfaction with the preprocess stage itself. 
5. Evaluate the trade-offs. Few strategies are without their trade-offs. While reducing duration can allow restaurants to serve more customers during peak demand periods, the benefit of the additional revenues and contribution generated could be outweighed by the negative outcome of reduced customer satisfaction. What this means is that restaurateurs must seek to reduce duration at the appropriate point in the meal and in appropriate ways.

\section{Conclusions and Further Research}

At its simplest level, reducing dining duration during peak demand periods will enable restaurant operators to generate additional revenue. Our study has shown, however, that this is not a simple matter, because of the possible damage to customer satisfaction of reducing duration. At the same time, though, we have identified certain dining stages and restaurant types where duration reduction should have a minimal effect on customer satisfaction.

Certain limitations to this study should be addressed in future studies. First, our study's findings are based on a convenience sample, and data were collected retrospectively. Our respondents' recollections were up to three weeks old, rather than taken directly following their meal. Future research using other sampling techniques and methods is needed to determine the robustness of the results. Second, the study did not capture all of the causes and consequences of customer satisfaction with dining experiences, nor was it intended to do so. Some of the factors for which we did not control may influence the relationship between perceived pace and customer satisfaction, for example, the volume of customers, volume and pace of the music, and the comfort of the physical facilities. Finally, different approaches that restaurant operators can use to reduce duration, including, for example, the use of cues, improving the consistency of service delivery, and reducing the time between customers (for a discussion of these approaches, see Kimes and Chase 1998), should be assessed to establish their potential impact on customer satisfaction.

\section{Appendix}

\section{Sample of Questionnaire}

\section{Service Experience Survey}

The purpose of this survey is to gain a better understanding of customer evaluations of service experiences. The survey is composed of two parts:

In Part One you will be asked to recall a meal experience that you have had in a restaurant and answer some general questions in relation to that experience.

In Part Two of the survey you will be asked to complete a number of sets of questions in relation to the experience that you have recalled.

NOTE: Your participation in this survey is purely voluntary and you may stop answering the questions at any time and for whatever reason.

\section{Part One}

In this study we are interested only in customer experiences in sit-down restaurants. This includes a number of different types of restaurants: casual restaurants (average check: $\$ 12$ 
to $\$ 20$, e.g., Applebee's, Chili's, T.G.I. Friday), upscale casual restaurants (average check: $\$ 20$ to \$30, e.g., PF Chang, Houstons), and fine-dining restaurants (average check: above \$30, e.g., Ruth's Chris Steakhouse, Le Cirque).

Please take a moment to review the following definition of a meal experience that we are using in this study:

\section{A meal experience begins when you are seated at your table and ends} when you vacate your table.

Typical activities that occur during this period include being greeted by your server; the ordering and delivery of drinks; the ordering, delivery and clearing of appetizers/entrees/desert and coffee; and the request, delivery and return of the check.

Now we would like you to take a couple of minutes to recall a recent occasion when you were out for lunch or dinner in a restaurant where there was an instance, or instances, during the meal when you felt that the pace of the meal was fast. Note: Depending on the circumstances, fast could either be a GOOD or a BAD thing.

Now please continue to the questions below.

Please answer the following questions in relation to your meal experience on this occasion:

1. What type of meal did you have on this specific occasion?

Lunch

Dinner

2. Approximately how long ago did this meal experience occur?

3. What type of restaurant were you in? Casual __ Upscale casual Fine dining Name of restaurant (optional):

4. Had you eaten in this specific restaurant before? Never 1-5 Times 6-10 Times $>10$ Times

5. Why did you go to a restaurant on this occasion? Please select one only. Social (out for a meal with family/friends, special occasion, celebration) Business __ Convenience

6. How many people dined in your party (including you)? Adults

Children

\section{Part Two}

In this part of the survey we would like you to continue to focus on the meal experience that you have recalled in Part One of the survey and answer a number of sets of questions in relation to that specific experience. There are four sections in this part of the survey. Please complete all sections.

\section{Section One}

In this section, we would like you to think specifically about the FIRST STAGE of the meal that you have recalled. For the purpose of this study, the following definition of the FIRST STAGE of a meal is being used: 
The FIRST STAGE of a meal begins at the time that you are seated at your table up to and including the point at which your server delivers your first food course to your table.

Typical interactions that occur during this stage include being greeted by your server, ordering drinks and delivery of drinks, ordering food, and delivery of your first food course.

1. To what extent do you agree with the following statement? How would you describe the pace of the FIRST STAGE of your meal? Extremely Fast: $1 \quad 2 \quad 2 \quad 3 \quad 4 \quad 5 \quad 6 \quad 7 \quad$ :Extremely Slow

2. How would you describe the length of the FIRST STAGE of your meal?

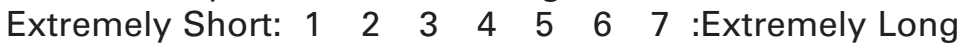
3. Overall, how would you rate the FIRST STAGE of your meal?
It pleased me:
$\begin{array}{llllllll}1 & 2 & 3 & 4 & 5 & 6 & 7 & \text { : It displeased me }\end{array}$ I was contented with it: $\quad \begin{array}{llllllll}1 & 2 & 3 & 4 & 5 & 6 & 7 & \text { : I was disgusted with it }\end{array}$

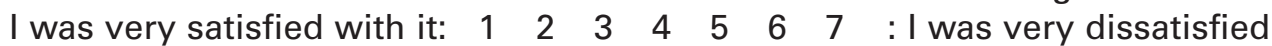 with it
$\begin{array}{llllllllll}\text { It did a good job for me: } & 1 & 2 & 3 & 4 & 5 & 6 & 7 & \text { : It did a poor job for me }\end{array}$ I was happy with it:
This restaurant was a $\begin{array}{llllllll}1 & 2 & 3 & 4 & 5 & 6 & 7 & \text { : I was unhappy with it }\end{array}$ wise choice:
$\begin{array}{llllllll}1 & 2 & 3 & 4 & 5 & 6 & 7 & \text { :This restaurant was a }\end{array}$ poor choice

\section{Section Two}

In this section, we would like you to think specifically about the SECOND STAGE of the meal that you have recalled. For the purpose of this study, the following definition of the SECOND STAGE of a meal is being used:

The SECOND STAGE of a meal begins at the time that you receive your first food course and lasts up until the point in time that either (1) you request your check or (2) the server automatically delivers the check (i.e., without your having requested it).

Typical interactions that occur during this stage include clearing of plates/glasses, delivery of entrees/dessert/coffee, receipt of dessert menu, ordering dessert/coffee, request (or automatic delivery without request) of the check.

1. To what extent do you agree with the following statement? How would you describe the pace of the SECOND STAGE of your meal? Extremely Fast: $1 \quad 2 \quad 2 \quad 3 \quad 4 \quad 5 \quad 6 \quad 6 \quad 7$ :Extremely Slow

2. How would you describe the length of the SECOND STAGE of your meal? Extremely Short: $1 \begin{array}{llllllll}1 & 2 & 3 & 4 & 5 & 6 & 7 & \text { :Extremely Long }\end{array}$

3. Overall, how would you rate the SECOND STAGE of your meal?

$\begin{array}{lllllllll}\text { It pleased me: } & 1 & 2 & 3 & 4 & 5 & 6 & 7 & \text { : It displeased me } \\ \text { I was contented with it: } & 1 & 2 & 3 & 4 & 5 & 6 & 7 & : \text { I was disgusted with it } \\ \text { I was very satisfied with it: } & 1 & 2 & 3 & 4 & 5 & 6 & 7 & \begin{array}{l}\text { : I was very dissatisfied } \\ \text { with it }\end{array} \\ \text { It did a good job for me: } & 1 & 2 & 3 & 4 & 5 & 6 & 7 & \text { : It did a poor job for me }\end{array}$


I was happy with it:

This restaurant was a wise choice: $\begin{array}{llllllll}1 & 2 & 3 & 4 & 5 & 6 & 7 & \text { : I was unhappy with it }\end{array}$

$\begin{array}{llllllll}1 & 2 & 3 & 4 & 5 & 6 & 7 & \text { :This restaurant was a }\end{array}$

\section{Section Three}

In this section, we would like you to think specifically about the THIRD STAGE of the meal that you have recalled. For the purpose of this study, the following definition of the THIRD STAGE of a meal is being used:

The THIRD STAGE of a meal begins at the time that either: (1) you request your check or (2) the server automatically delivers the check (i.e., without your having requested it) to the time that you vacate your table.

Typical interactions that occur during this stage include the server clearing dessert plates and other items from the table, refilling your coffee, delivering and collecting the check and returning the check to the table.

1. To what extent do you agree with the following statement?

How would you describe the pace of the THIRD STAGE of your meal?

Extremely Fast: $1 \begin{array}{llllllll}1 & 2 & 3 & 4 & 5 & 6 & 7 & \text { :Extremely Slow }\end{array}$

2. How would you describe the length of the THIRD STAGE of your meal?

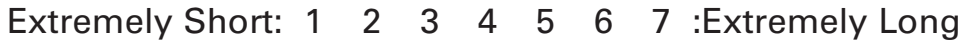

3. Overall, how would you rate the THIRD STAGE of your meal?

$\begin{array}{lllllllll}\text { It pleased me: } & 1 & 2 & 3 & 4 & 5 & 6 & 7 & \text { : It displeased me } \\ \text { I was contented with it: } & 1 & 2 & 3 & 4 & 5 & 6 & 7 & : \text { I was disgusted with it } \\ \text { I was very satisfied with it: } & 1 & 2 & 3 & 4 & 5 & 6 & 7 & \text { : I was very dissatisfied } \\ \text { with it }\end{array}$

$\begin{array}{llllllllll}\text { It did a good job for me: } & 1 & 2 & 3 & 4 & 5 & 6 & 7 & \text { : It did a poor job for me }\end{array}$

$\begin{array}{llllllllll}\text { I was happy with it: } & 1 & 2 & 3 & 4 & 5 & 6 & 7 & \text { : I was unhappy with it }\end{array}$

$\begin{array}{llllllllll}\text { This restaurant was } & 1 & 2 & 3 & 4 & 5 & 6 & 7 & \text { :This restaurant was a }\end{array}$

a wise choice:

poor choice

\section{Section Four}

In this section, we would like you to think about the meal that you have recalled IN ITS

ENTIRETY and answer the following questions.

1. How would you rate your OVERALL impression of this meal?

It pleased me: $\quad \begin{array}{lllllllll} & 2 & 2 & 3 & 4 & 5 & 6 & 7 & \text { : It displeased me }\end{array}$

I was contented with it: $\quad \begin{array}{lllllllll}1 & 2 & 3 & 4 & 5 & 6 & 7 & \text { : I was disgusted with it }\end{array}$

I was very satisfied with it: $\quad \begin{array}{llllllll}1 & 2 & 3 & 4 & 5 & 6 & 7 & \text { : I was very dissatisfied }\end{array}$ with it

$\begin{array}{lllllllll}\text { It did a good job for me: } & 1 & 2 & 3 & 4 & 5 & 6 & 7 & \text { : It did a poor job for me }\end{array}$

I was happy with it: $\quad \begin{array}{llllllllll}1 & 2 & 3 & 4 & 5 & 6 & 7 & \text { : I was unhappy with it }\end{array}$

$\begin{array}{llllllllll}\text { This restaurant was a } & 1 & 2 & 3 & 4 & 5 & 6 & 7 & \text { :This restaurant was a }\end{array}$

wise choice: poor choice

2. How would you describe the OVERALL pace of your meal?

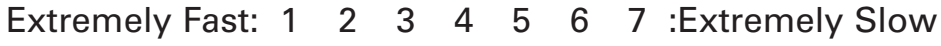

3. How would you describe the OVERALL length of your meal?

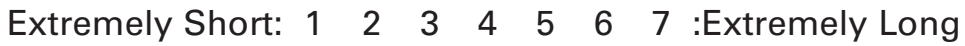




\section{References}

Anderson, E. W. 1998. Customer satisfaction and word-ofmouth. Journal of Service Research 1:1-14.

Anderson, E. W., and M. W. Sullivan. 1993. The antecedents and consequences of customer satisfaction for firms. Marketing Science 12 (2): 125-43.

Bhatia, P. 2002. Hurry up and eat. Wall Street Journal, June 21, p. W1.

Bolton, R. N. 1998. A dynamic model of the duration of the customer's relationship with a continuous service provider: The role of satisfaction. Marketing Science 17 (1): 45-65.

Bolton, R. N., and J. H. Drew. 1991. A longitudinal analysis of the impact of service changes on customer attitudes. Journal of Marketing 55 (1): 1-10.

Bolton, R. N., and K. N. Lemon. 1999. A dynamic model of customers' usage of services: Usage as an antecedent and consequence of satisfaction. Journal of Marketing Research 36:171-86.

Davis, M. M., and M. J. Maggard. 1994. Zero waiting time: A model for designing fast and efficient service delivery systems. In Advances in services marketing and management-Research and practice, ed. T. A. Swartz, D. E. Bowen, and S. W. Brown. Greenwich, CT: JAI.

Dubé-Rioux, L., B. H. Schmitt, and F. Leclerc. 1989. Consumers' reactions to waiting: When delays affect the perception of service quality. Advances in Consumer Research 16 (1): 59-63.

Hanks, R. D., R. G. Cross, and R. P. Noland. 1992. Discounting in the hotel industry: A new approach. Cornell Hotel and Restaurant Administration Quarterly 33 (1): $15-23$.

Higgins, M. 2004. Grocery shopping enters a new age: Handheld gizmo lets you scan items before you get to the checkout counter. Wall Street Journal, March 30, p. D4.

Hui, M. K., and D. Tse. 1996. What to tell consumers in waits of different lengths: An integrative model of service evaluation. Journal of Marketing 60 (2): 81-90.

Jones, P., and M. Dent. 1994. Improving service: Managing response time in hospitality operations. International Journal of Operations and Production Management 14 (5): 52-58.

Katz, K. L., B. M. Larson, and R. C. Larson. 1991. Prescription for the waiting-in-line blues: Entertain, enlighten and engage. Sloan Management Review 32 (2): 44-53.

Kimes, S. E. 1989. The basics of yield management. Cornell Hotel and Restaurant Administration Quarterly 30 (3): 14-19.

. 2000. Revenue management on the links. Cornell Hotel and Restaurant Administration Quarterly 41 (1): 120-27.

Kimes, S. E., and R. B. Chase. 1998. The strategic levers of yield management. Journal of Service Research 1 (2): $156-66$.

Kimes, S. E., R. B. Chase, S. Choi, P. Y. Lee, and E. N. Ngonzi. 1998. Restaurant revenue management: Applying yield management to the restaurant industry. Cornell Hotel and Restaurant Administration Quarterly 39 (3): 32-39.

Kimes, S. E., and J. Wirtz. 2002. Perceived fairness of revenue management in the golf industry. Journal of Revenue and Pricing Management 1 (4): 322-43.
2003. Has revenue management become acceptable? Findings from an international study on the perceived fairness of rate fences. Journal of Service Research 6 (2): 125-35.

Kimes, S. E., J. Wirtz, and B. M. Noone. 2002. How long should dinner take? Measuring expected meal duration for restaurant revenue management. Journal of Revenue and Pricing Management 1 (3): 220-33.

LaBarbera, P. A., and D. Mazursky. 1983. A longitudinal assessment of consumer satisfaction/dissatisfaction: The dynamic aspect of the cognitive process. Journal of Marketing Research 20 (4): 393-404.

Mittal, V., K. Pankaj, and M. Tsiros. 1999. Attribute-level performance, satisfaction, and behavioral intentions over time: A consumption-system approach. Journal of Marketing 63 (2): 88-101.

New-Fielding, S. 2002. First with the news: WHSmith achieves $50 \%$ reduction in customer waiting time European Retail Digest 35:1-3.

Pruyn, A., and A. Smidts. 1998. Effects of waiting on the satisfaction with the service: Beyond objective time measurements. International Journal of Research in Marketing 15 (4): 321-34.

Secomandi, N., K. Abbott, T. Atam, and E. Andrew Boyd. 2002. From revenue management concepts to software systems. Interfaces 32 (2): 1-11.

Sheu, C., and S. Babbar. 1996. A managerial assessment of the waiting-time performance for alternative service process designs. Omega-The International Journal of Management Science 24 (6): 689, 703.

Sill, B. T. 1991. Capacity management: Making your service delivery more productive. Cornell Hotel and Restaurant Administration Quarterly 42 (1): 77-87.

Smith, B. C., J. F. Leimkuhler, and R. M. Darrow. 1992. Yield management at American Airlines. Interfaces 22 (1): 8-31.

Szuchman, P., and W. Tesoriero. 2004. Hurry up and putt-With iron hand, golf marshals get rough on slow duffers: Mr. Blanco's marching orders. Wall Street Journal, April 9, W1.

Taylor, S. 1994. Waiting for service: The relationship between delays and evaluations of service. Journal of Marketing 58 (2): 56-69.

Tom, G., and S. Lucey. 1997. A field study investigating the effect of waiting time on customer satisfaction. Journal of Psychology 131 (6): 655-60.

Westbrook, R. A., and R. L. Oliver. 1981. Developing better measures of consumer satisfaction: Some preliminary results. Advances in Consumer Research 8 (1): 94-99.

Wirtz, J., and P. Chew. 2002. The effects of incentives, deal proneness, satisfaction and tie strength on word-ofmouth behaviour. International Journal of Service Industry Management 13 (2): 141-62.

Wirtz, J., S. E. Kimes, J. P. T. Ho, and P. Patterson. 2003. Revenue management: Resolving potential customer conflicts. Journal of Revenue and Pricing Management 2 (3): 216-28.

Woodruff, R. B., E. R. Cadotte, and R. L. Jenkins. 1983. Modeling consumer satisfaction process using experience-based norms. Journal of Marketing Research 20 (3): 296-304. 
Breffni M. Noone, Ph.D., is an assistant professor at The Pennsylvania State University School of Hospitality Management (bmn2@ psu.edu). Sheryl E. Kimes, Ph.D., is a professor at the Cornell University School of Hotel Administration (sek9@cornell.edu). Anna S. Mattila, Ph.D., is an associate professor at The Pennsylvania State University School of Hospitality Management (asm6@psu.edu). Jochen Wirtz, Ph.D., is an associate professor at the NUS Business School, the National University of Singapore (bizwirtz@ nus.edu.sg). 